\title{
Engineering a synthetic anaerobic respiration for reduction of xylose to xylitol using NADH output of glucose catabolism by Escherichia coli Al21
}

Andrew Iverson ${ }^{1,2,3}$, Erin Garza ${ }^{1,2}$, Ryan Manow ${ }^{1,2}$, Jinhua Wang ${ }^{1 *}$, Yuanyuan Gao ${ }^{4}$, Scott Grayburn ${ }^{2}$ and Shengde Zhou ${ }^{1,2^{*}}$

\begin{abstract}
Background: Anaerobic rather than aerobic fermentation is preferred for conversion of biomass derived sugars to high value redox-neutral and reduced commodities. This will likely result in a higher yield of substrate to product conversion and decrease production cost since substrate often accounts for a significant portion of the overall cost. To this goal, metabolic pathway engineering has been used to optimize substrate carbon flow to target products. This approach works well for the production of redox neutral products such as lactic acid from redox neutral sugars using the reducing power NADH (nicotinamide adenine dinucleotide, reduced) generated from glycolysis (2 NADH per glucose equivalent). Nevertheless, greater than two NADH per glucose catabolized is needed for the production of reduced products (such as xylitol) from redox neutral sugars by anaerobic fermentation.

Results: The Escherichia coli strain Al05 ( $\Delta$ frdBC $\Delta / d h A \Delta a c k A \Delta$ (focA-pflB) $\triangle a d h E \Delta p t s G \Delta p d h R:: p f l B p_{6}$-(aceEF-lpd)), previously engineered for reduction of xylose to xylitol using reducing power (NADH equivalent) of glucose catabolism, was further engineered by 1) deleting $x y \mid A B$ operon (encoding for $x y l o s e$ isomerase and xylulokinase) to prevent xylose from entering the pentose phosphate pathway; 2 ) anaerobically expressing the sdhCDAB-suCABCD operon (encoding for succinate dehydrogenase, a-ketoglutarate dehydrogenase and succinyl-CoA synthetase) to enable an anaerobically functional tricarboxcylic acid cycle with a theoretical $10 \mathrm{NAD}(\mathrm{P}) \mathrm{H}$ equivalent per glucose catabolized. These reducing equivalents can be oxidized by synthetic respiration via xylose reduction, producing xylitol. The resulting strain, Al21 (pAl02), achieved a $96 \%$ xylose to xylitol conversion, with a yield of 6 xylitol per glucose catabolized (molar yield of xylitol per glucose consumed $\left(Y_{\mathrm{RPG}}\right)=6$ ). This represents a $33 \%$ improvement in xylose to xylitol conversion, and a $63 \%$ increase in xylitol yield per glucose catabolized over that achieved by Al05 (pAl02).

Conclusions: Increasing reducing power (NADH equivalent) output per glucose catabolized was achieved by anaerobic expression of both the $p d h$ operon (pyruvate dehydrogenase) and the sdhCDAB-suCABCD operon, resulting in a strain capable of generating $10 \mathrm{NADH}$ equivalent per glucose under anaerobic condition. The new E. coli strain Al21 (pAl02) achieved an actual $96 \%$ conversion of xylose to xylitol (via synthetic respiration), and 6 xylitol (from xylose) per glucose catabolized ( $Y_{\mathrm{RPG}}=6$, the highest known value). This strategy can be used to engineer microbial strains for the production of other reduced products from redox neutral sugars using glucose as a source of reducing power.
\end{abstract}

Keywords: E. coli, NADH output, Reducing power, sdhCDAB-suCABCD operon, Synthetic respiration

\footnotetext{
* Correspondence: szhou@niu.edu

${ }^{1}$ Hubei Provincial Cooperative Innovation Center of Industrial Fermentation, Key Laboratory of Fermentation Engineering (Ministry of Education), College of Bioengineering, Hubei University of Technology, Wuhan 430068, PR China ${ }^{2}$ Department of Biological Sciences, Northern Illinois University, DeKalb, IL 60115, USA

Full list of author information is available at the end of the article
} 


\section{Background}

Promising technologies are continuing to be developed for the conversion of cellulosic biomass into value-added commodities via microbial fermentation [4]. In order to be an economically viable process, however, anaerobic rather than aerobic microbial fermentation will most likely be used to produce redox neutral and reduced products. The anaerobic process will achieve a high substrate to product conversion yield since substrates often account for a significant portion of the production cost. To this end, metabolic pathway engineering has been used to optimize carbon flow from biomass-derived sugars to final products at high yields through manipulation of enzyme levels by over-expression, addition and/ or deletion of target pathway genes [21]. Nevertheless, the insufficient supply of reducing power NADH (nicotinamide adenine dinucleotide, reduced) equivalent output of sugar catabolism remains a significant challenge for the production of reduced products from redox neutral biomass derived sugars under anaerobic conditions.

Most, if not all, microbial species can obtain a fixed number of NADH from any given carbon source under anaerobic conditions (e. g. two NADH can be formed from glycolysis by E. coli grown anaerobically). While limited, these NADH outputs provide the reducing power for the reduction of metabolic intermediates into fermentation products. In nature, with the limited NADH available from catabolism, some microorganisms have evolved multiple fermentation pathways to produce a mixture of redox neutral, oxidized, and reduced products to achieve a balanced redox in the absence of a suitable terminal electron acceptor. For example, under anaerobic conditions, E. coli carries out a mixed acid fermentation using the two $\mathrm{NADH}$ from glycolysis, producing oxidized (formic acid and succinic acid), redox neutral (acetic acid and lactic acid), and reduced (ethanol) products [8]. Genetic engineering has been successfully used to divert carbon flow and the reducing power (NADH) to produce redox neutral products, such as lactic acid, with a $100 \%$ theoretical yield $[25,27]$. Nevertheless, NADH availability from glucose catabolism often limits the yield of reduced products by anaerobic $E$. coli fermentation [13].

Increasing NADH availability, at least in theory, will accordingly increase the yield of reduced product via anaerobic fermentation. In prior studies, alteration of the $\mathrm{NADH} / \mathrm{NAD}$ ratios by growing cells on carbon sources of various oxidative states $[2,15]$, or through supplementation of alternative electron acceptors [11], did indeed increase the proportion of reduced products from mixed acid fermentation of E. coli. In addition, Berríos-Rivera [5] increased the intracellular NADH availability two-fold through heterologous expression of a $\mathrm{NAD}^{+}$-dependent formate dehydrogenase (regenerating NADH) from Candida boidinii in $E$. coli, which resulted in a significant shift to reduced product (ethanol) accumulation and a dramatic increase in the ethanol-to-acetate ratio [6]. Furthermore, Cirino et al. [7] increased the NADH output of glucose catabolism by using an $E$. coli mutant with an anaerobic functional pyruvate dehydrogenase (PDH). Improved xylitol (a reduced product) yield was achieved from xylose reduction using the NADH output of glucose metabolism by this mutant.

Previously, we engineered E. coli SZ420, a strain with a doubled reducing power output through anaerobic expression of pyruvate dehydrogenase (aceEF-lpd), establishing a homoethanol pathway (glucose $=>$ glycolysis $=>2$ $\mathrm{NADH}+2$ pyruvate $=>$ anaerobically synthesized pyruvate dehydrogenase $=>2$ acetyl-CoA $+4 \mathrm{NADH}=>$ alcohol dehydrogenase $=>2$ ethanol) $[28,29]$. Subsequently, SZ420 was engineered for reduction of xylose to xylitol (via synthetic respiration) using the reducing power of glucose catabolism by: 1) deleting the alcohol dehydrogenase ( $a d h E)$ gene; 2$)$ deleting the glucose-specific PTS permease complex (ptsG) to remove catabolic repression and allow simultaneous glucose and xylose uptake; and 3) expressing the aldose reductase gene $(x y l)$ from $C$. boidinii [13]. The resulting strain, AI05 (pAI02), achieved a xylose to xylitol conversion ratio of 1:0.72, and a yield of 3.6 xylitol (from xylose) per glucose catabolized, with acetate as a minor by-product.

In this study, we report further engineering of E. coli AI05 with increased NADH output from glucose catabolism for effective reduction of xylose to xylitol by: 1) completely blocking xylose from entering the pentose phosphate pathway through deletion of genes encoding for xylose isomerase $(x y l A)$ and xylulokinase $(x y l B) ; 2)$ activation of an anaerobic TCA (tricarboxylic acid) cycle through anaerobic expression of the sdhCDAB-sucABCD operon, which encodes for succinate dehydrogenase $(s d h C D A B)$, the $\alpha$-ketoglutarate dehydrogenase complex (sucAB), and succinyl-CoA synthetase $(\operatorname{suc} C D)$. The resulting strain, AI21 (pAI02), achieved a xylose-to-xylitol conversion ratio of 1:1, a yield of 6 xylitol per glucose catabolized, and lacked acetate by-product accumulation.

\section{Methods}

Strains, plasmids, media, and growth conditions

Bacterial strains, plasmids and primers used in this study are listed in Table 1. For plasmid and strain construction, cultures were grown in Luria-Bertani (LB) broth $(\mathrm{g} / \mathrm{L}$ : tryptone 10 , yeast extract $5, \mathrm{NaCl} 5$ ) or on LB plates (agar $15 \mathrm{~g} / \mathrm{L}$ ). For enzymatic and NAD/NADH assays, cultures were grown in mineral salts medium broth $\left(\mathrm{g} / \mathrm{L}: \mathrm{KH}_{2} \mathrm{PO}_{4}\right.$ 3.5, $\mathrm{K}_{2} \mathrm{HPO}_{4}$ 5.0, $\left(\mathrm{NH}_{4}\right)_{2} \mathrm{HPO}_{4}, \quad \mathrm{MgSO}_{4}: 7 \mathrm{H}_{2} \mathrm{O} \quad 0.25$, $\mathrm{CaCl}_{2}: 2 \mathrm{H}_{2} \mathrm{O} .015$, thiamine 0.0005 , and $1 \mathrm{~mL}$ of trace metal stock) [27]. Antibiotics were included in the media as needed at the following concentrations: kanamycin and ampicillin, $50 \mu \mathrm{g} / \mathrm{mL}$; chloramphenicol, $40 \mu \mathrm{g} / \mathrm{mL}$. 
Table 1 E. coli strains, plasmids, and primers used in this study

\begin{tabular}{|c|c|c|}
\hline Strains & Relevant characteristics & Sources \\
\hline B & Wild type & ATCC11303 \\
\hline SZ420 & E. coli B, $\Delta$ frdBC $\Delta / d h A \Delta a c k A \Delta(f o c A-p f l B) \Delta p d h R:: p f l B p_{(6)}-(a c e E F-l p d)$ & Zhou et al. [28] \\
\hline Al03 & E. coli SZ420, $\triangle a d h E$ & Iverson et al. [13] \\
\hline Al05 & E. coli SZ420, $\Delta a d h E \Delta p t s G$ & Iverson et al. [13] \\
\hline Al09 & E. coli SZ420, $\Delta a d h E \Delta p t s G \Delta x y l B$ & This study \\
\hline Al12 & E. coli SZ420, $\Delta a d h E \Delta p t s G \Delta x y \mid B \Delta s d h C p .: F n r$ box- $p f \mid B p_{(6)}-(s d h C D B A-s u C A B C D)$ & This study \\
\hline Al21 & E. coli SZ420, $\Delta a d h E \Delta p t s G \Delta x y|B \Delta x y| A \Delta s d h C p:: F n r$ box- $p f l B p_{(6)}-(s d h C D B A-s u C A B C D)$ & This study \\
\hline \multicolumn{3}{|l|}{ Plasmids } \\
\hline pKD4 & bla, FRT-km-FRT & Datsenko and Wanner [10] \\
\hline pKD46 & bla, y $\beta$ exo (red recombinase), temperature-conditional replicon & Datsenko and Wanner [10] \\
\hline pFT-A & bla, flp, temperature-conditional replicon & Posfai et al. [19] \\
\hline pUC19 & bla cloning vector & NE Biolab \\
\hline pSD105 & $\begin{array}{l}\text { PCR amplified } 0.35 \mathrm{~kb} \text { pflB promoter region (BamHI- } \mathrm{pflBp}_{6} \text {-HindIII) was inserted into pSD101 } \\
\text { at BamHI and HindllI sites }\end{array}$ & Zhou et al. [29] \\
\hline pAGI02 & PCR amplified $0.966 \mathrm{~kb}$ xyll region from C. boidinii was inserted into pSD105 at HindIII site & Iverson et al. [13] \\
\hline \multicolumn{3}{|l|}{ Primers $^{\mathrm{a}}$} \\
\hline$\Delta x y \mid B N$-primer & atgtatatcgggatagatcttggcacctcgggcgtaaaagttattgtgtaggctggagatgcttc & This study \\
\hline$\Delta x y / B$ C-primer & ttacgccattaatggcagaagttgctgatagaggcgacggaacgtcatatgatatcctccttag & This study \\
\hline$\Delta x y / A$ N-primer & ccgcggcattacctgattatggagttcaatatgcaagcctattttggtgtaggctggagatgcttc & This study \\
\hline$\Delta x y / A$ C-primer & gttatttgtcgaacagataatggtttaccagattttccagttgttccatatgaatatcctccttag & This study \\
\hline Integration primer 1 & 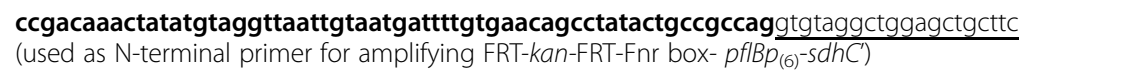 & This study \\
\hline Integration primer 2 & $\begin{array}{l}\text { gaaccggatggtctgtaggtccagattaacaggtctttgtttttcacatttcttatcatgtaacacctaccttctgttgctgtgatatagaagac } \\
\text { (used as C-terminal primer for amplifying FRT-kan-FRT-pflBp } p_{6}-s d h C \text { ) }\end{array}$ & This study \\
\hline rrsA primer 1 & cggtggagcatgtggtttaa (used for qt-PCR) & Nishino et al. [18] \\
\hline $\operatorname{rrs} A$ primer 2 & gaaaacttccgtggatgtcaaga(used for qt-PCR) & Nishino et al. [18] \\
\hline sdhC primer 1 & cgccagccgcccagcacag (used for qt-PCR) & This study \\
\hline sdhC primer 2 & ggtatggaaggtctgttccgtcagattggtatttacagccc (used for qt-PCR) & This study \\
\hline sucA primer 1 & cagggcggttgcttcaccatctcca (used for qt-PCR) & This study \\
\hline sucA primer 2 & gcggcacgaactctttaccattccacacc (used for qt-PCR) & This study \\
\hline
\end{tabular}

${ }^{a}$ The underlined sequence of $\triangle x y / B \mathrm{~N}$-primer, $\triangle x y / A \mathrm{~N}$-primer and intergration primer 1 is corresponding to primer 1 of pKD4; The underlined sequence of $\triangle x y / B$ C-primer and $\triangle x y \mid A$ C-primer is corresponding to the primer 2 of pKD46; the bold sequence of integration primer 1 is corresponding to the -219 to $-174 \mathrm{bp}$ upstream region of $s d h C$; the bold sequence of integration primer 2 is corresponding to the +1 to +45 of the $s d h C$ coding sequence; The italicized sequence of integration primer 2 is corresponding to the $16 \mathrm{bp}$ ribosomal binding site of $p f B$

\section{Genetic methods}

Standard methods were used for plasmid construction, transformation, electroporation, and PCR $[16,20]$. Chromosomal gene deletions were constructed using procedures developed by Posfai et al. [19] and Datsenko and Wanner [10]. Briefly, hybrid primer pairs were designed as follows: part of the primer is complementary to the deletion target gene and part complementary to the antibiotic cassette (FRT-kan-FRT) of pKD4 [10]. The amplified DNA, using these primer pairs and pKD4 as the template, was purified and electroporated into $E$. coli AI05 or its derivative (transformed with pKD46) using a micropulser (Bio-rad laboratories). As a result, the target gene was replaced by the FRT-kan-FRT cassette through homologous recombination (double crossover), resulting in kanamycin-resistant colonies. After streak-plate purification, the isolated colonies were verified by PCR analysis. The antibiotic marker cassette (FRT-kan-FRT) that was integrated onto the chromosome was then removed through FRT site-specific recombination via a flipase (FLP recombinase encoded by pFT-A, a temperatureconditional helper plasmid [19]).

Transcriptional fusion of the $s d h C D A B$-sucABCD operon The pflBp6-sdhCDAB-sucABCD transcriptional fusion (Fig. 1b) was constructed using previously described procedures [28, 29]. Hybrid primers were designed as follows (Table 1): the integration primer 1 consists of $45 \mathrm{bp}$ 


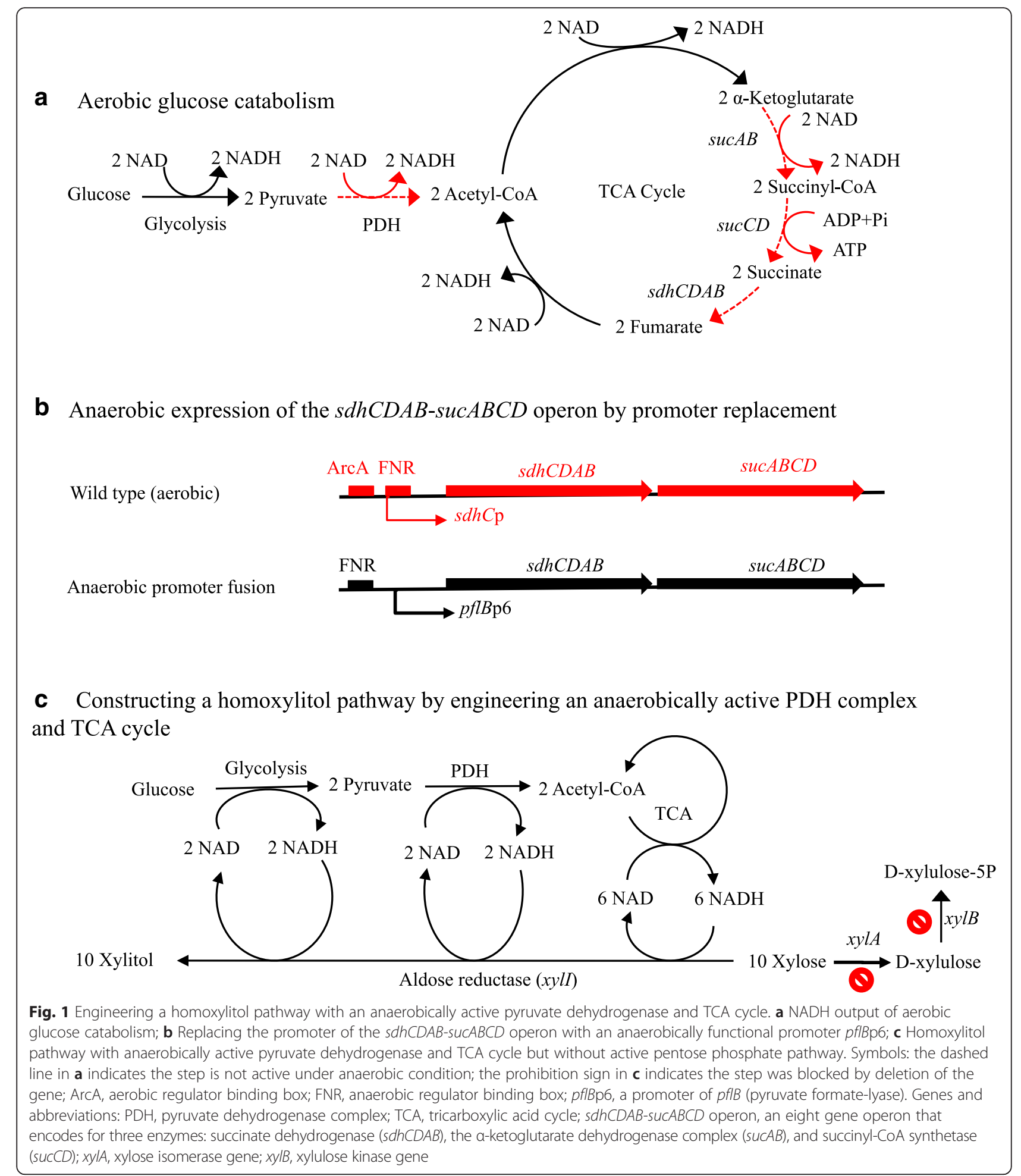

corresponding to the -219 to -174 bp upstream region of $s d h C$, accompanied by a 20 bp sequence corresponding to primer 1 of pKD4; the integration primer 2 consists of $45 \mathrm{bp}$ corresponding to +1 to +45 of the $s d h C$ coding sequence, followed by the 16 bp ribosomal binding site of $p f l B$ and a $20 \mathrm{bp} p f l B \mathrm{p} 6$ promoter sequence. A FRT-kan-FRT-pflBp6-pflBrbs product was amplified by PCR using the hybrid primer pair and pSD105 as the template, which contains the pflBp6 promoter and an upstream FNR-box $(0.35 \mathrm{~kb})$ derived from 
E. coli B [29]. Following purification, the amplified product $(\sim 2 \mathrm{~kb})$ was electroporated into E. coli AI09 (transformed with pKD46). The resulting kanamycin-resistant recombinant colonies contained the transcriptional fusion of the FNR box, $p f l B \mathrm{p} 6$ promoter, $p f l B$ ribosomal binding site, and the coding sequence of the $s d h C D A B$ sucABCD operon (Fig. 1b). After verification of this chromosomal gene fusion by analysis of the PCR products, the antibiotic marker ( $k a n)$ was removed from the chromosome with the pFT-A encoded FLP recombinase as described previously.

\section{Enzymatic assays}

Bacterial cells were grown (100 rpm or $200 \mathrm{rpm}, 37^{\circ} \mathrm{C}$ ) to mid-log phase in $250 \mathrm{~mL}$ flasks containing $50 \mathrm{~mL}$ mineral salts broth supplemented with $50 \mathrm{mM}$ succinate or $\alpha$-ketoglutarate. These cells were pelleted, resuspended either in $10 \mathrm{~mL} 1 \times$ Tris buffer $(\alpha$-ketoglutarate: $100 \mathrm{mM}$ Tris, $2 \mathrm{mM}$ dithiothreitol, $\mathrm{pH}$ 8.5) or potassium phosphate buffer (succinate dehydrogenase: $100 \mathrm{mM}$ potassium phosphate, $\mathrm{pH} 7.4$ ), cooled on ice for $20 \mathrm{~min}$, and sonicated 3 times (10 s each round) using a Sonifier Cell Distributor W-350 (Branson Sonic Power Inc.). After centrifugation at $4{ }^{\circ} \mathrm{C}(5000 \mathrm{rpm})$, the sonicated cell broth supernatant was used as crude extract for the assays. The $\alpha$-ketoglutarate dehydrogenase assay was performed using the following method [3]: $650 \mu \mathrm{L}$ of Tris buffer (200 mM, $2 \mathrm{mM}$ DTT, pH 8.5) and $150 \mu \mathrm{L}$ of each of the following $10 \times$ components were added to a $1.5 \mathrm{~mL}$ quartz cuvette: $\alpha$-ketoglutarate potassium salt $(80.4 \mathrm{mM}), 3$-acetylpyridine adenine dinucleotide $(20 \mathrm{mM})$, coenzyme A $(0.87 \mathrm{mM})$, L-cysteine hydrochloride $(20.6 \mathrm{mM})$. The reaction was initiated by adding $100 \mu \mathrm{L}$ of the crude extract, with the absorbance read at $363 \mathrm{~nm}$ for $5 \mathrm{~min}$ using a UV-2401PC UV-VIS Recording Spectrophotometer (Shimadzu). All components without $\alpha$-ketoglutarate potassium salt were used as the blank. One unit of enzyme activity was calculated as micromoles of 3-acetylpyridine adenine dinucleotide reduced per minute per mg of cell dry mass. The succinate dehydrogenase assay was performed using the following method [12]: $1.35 \mathrm{~mL}$ of potassium phosphate buffer $(0.1 \mathrm{mM}, \mathrm{pH} 7.4)$ and $30 \mu \mathrm{L}$ of each of the following $10 \times$ components were added to a $1.5 \mathrm{~mL}$ quartz cuvette: potassium cyanide $(6.5 \mathrm{mg} / \mathrm{mL}$ buffer $), 2,6$ dichlorophenol indophenol (DCIP) $(0.6 \mathrm{mg} / \mathrm{mL})$, phenazine methosulfate $(20 \mathrm{mg} / \mathrm{mL})$, disodium succinate $(54 \mathrm{mg} / \mathrm{mL})$. The reaction was initiated by adding $30 \mu \mathrm{L}$ of the crude extract, with the absorbance read at $600 \mathrm{~nm}$ for $8 \mathrm{~min}$. All components without disodium succinate were used as the blank. One unit of enzyme activity was calculated as micromoles of DCIP reduced per minute per mg of cell dry mass. Assays were performed in triplicate.

\section{$\mathrm{NADH} / \mathrm{NAD}$ assay}

The NADH/NAD concentrations were analyzed using adapted methods of Wimpenny and Firth [26]. Bacterial cells were grown to $\sim 1.0 \mathrm{OD}_{550}$ in LB broth $(50 \mathrm{~mL})$ containing $2 \%$ glucose at $37{ }^{\circ} \mathrm{C}$ under aerobic and oxygen limiting conditions. These cells were pelleted, and either treated with $300 \mu \mathrm{L} \mathrm{HCl}(200 \mathrm{mM}, \mathrm{pH}$ 1.5) for NAD extraction or with $300 \mu \mathrm{L} \mathrm{KOH}(200 \mu \mathrm{mM}$, $\mathrm{pH}$ 11.5) for NADH extraction. The cells were then incubated at $50{ }^{\circ} \mathrm{C}$ for $10 \mathrm{~min}$, cooled to $4{ }^{\circ} \mathrm{C}$, and then neutralized by adding $300 \mu \mathrm{L}$ either $100 \mathrm{mM} \mathrm{NaOH}$ (for $\mathrm{NAD}$ ) or $100 \mathrm{mM} \mathrm{HCl}$ (for NADH). After centrifugation, the supernatants were used for the NADH/NAD assays which were performed in a $1.5 \mathrm{ml}$ cuvette as follows: $400 \mu \mathrm{L}$ mixed solution (maintained at $30{ }^{\circ} \mathrm{C}$ ) containing equal amount of 3-(4,5-dimethyl-2-thiazolyl)2,5-diphenyl-2H-tetrazolium bromide $(4.2 \mathrm{mM})$, EDTA $(40 \mathrm{mM})$, Tris ( $1 \mathrm{M}, \mathrm{pH} 8.0)$, and $95 \%$ ethanol; $300 \mu \mathrm{L}$ $\mathrm{H}_{2} \mathrm{O} ; 200 \mu \mathrm{L}$ phenazine ethosulfate $(33.2 \mathrm{mM})$; and $50 \mu \mathrm{L}$ sample supernatant. The reaction was initiated by adding $50 \mu \mathrm{L}$ yeast alcohol dehydrogenase II $(500$ $\mathrm{U} / \mathrm{mL}$ ), and the absorbance was read at $570 \mathrm{~nm}$ for 5 min using a UV-2401PC UV-VIS Recording Spectrophotometer (Shimadzu). All components except ethanol were used as the blank. All assays were performed in triplicate.

\section{Quantitative real-time PCR}

E. coli $\mathrm{SZ} 420$ and its derivatives were grown to $\sim 1.5$ $\mathrm{OD}_{550}$ in $250 \mathrm{ml}$ screw-cap flasks containing $100 \mathrm{ml}$ mineral salts media broth supplemented with either $50 \mathrm{mM}$ glucose, $50 \mathrm{mM}$ succinate, or $50 \mathrm{mM} \alpha$ ketoglutarate $\left(37^{\circ} \mathrm{C}\right.$, shaking at $\left.100 \mathrm{rpm}\right)$. Bacterial cells (40 ml) were pelleted at $4{ }^{\circ} \mathrm{C}$, resuspended by vortexing in $1 \mathrm{ml}$ Tris-EDTA buffer $(10 \mathrm{mM}, \mathrm{pH} 8.0,0.1 \mathrm{mM}$ EDTA, $1 \mathrm{mg}$ of lysozyme), and mixed with $5 \mu \mathrm{l}$ of $10 \%$ SDS at $25^{\circ} \mathrm{C}$. From the cell suspension, $100 \mu \mathrm{L}$ was extracted and total RNA was isolated using the PureLink RNA mini kit (Invitrogen) as described for bacterial cells. Extracted RNA was treated with RQ1 RNase-Free DNase (Promega Corp., Madison, WI) to remove residual chromosomal DNA. The RNA was then used for cDNA synthesis and qPCR analysis of sdhCDABsuc $A B C D$ expression using the methods described previously $[25,29]$.

\section{Fermentations}

For anaerobic cell growth and fermentations, the culture were inoculated in media that became essentially anaerobic as the growing cells consumed the small amount of oxygen present in the media, rather than by inoculating cells into anaerobic media under strictly anaerobic conditions. Specifically, seed cultures were prepared by inoculating a single colony from a fresh plate into $50 \mathrm{ml}$ 
mineral salts broth containing $2 \%$ glucose (kanamycin added for maintaining plasmid pAI02) and incubating $\left(30{ }^{\circ} \mathrm{C}, 100 \mathrm{rpm}\right)$ to $\sim 2.0-4.0 \mathrm{OD}_{550}$. After centrifugation, cell suspensions were used to inoculate (initial 0.05 $\left.\mathrm{OD}_{550}\right) 250 \mathrm{ml}$ screw-cap flasks containing $100 \mathrm{ml} \mathrm{min-}$ eral salts medium supplemented with $5 \mathrm{~g} \mathrm{~L}^{-1}$ glucose, $15 \mathrm{~g} \mathrm{~L}^{-1}$ xylose and $100 \mu \mathrm{l}$ kanamycin. The flasks were then sealed by rubber caps. The fermentations were carried out in triplicate at $30{ }^{\circ} \mathrm{C}, 100 \mathrm{rpm}$ shaking, and supplementation of $20 \mu \mathrm{l}$ kanamycin every $24 \mathrm{~h}$ to maintain the plasmid. Samples were taken every $24 \mathrm{~h}$ for analysis of cell mass and concentration of sugars and fermentation products.

\section{Resting cell fermentation}

Methods were adapted from previously described procedures [7]. Seed cultures were prepared by inoculating a single colony from a fresh plate into $100 \mathrm{ml}$ mineral salts medium broth containing $2 \%$ glucose, $1 \%$ xylose, and $100 \mu \mathrm{l}$ kanamycin and then incubated $\left(30{ }^{\circ} \mathrm{C}, 100 \mathrm{rpm}\right)$ until $~ 2.0-4.0 \mathrm{OD}_{550}$. After centrifugation, cells were inoculated (initial $2.0 \mathrm{OD}_{550}$ ) into $250 \mathrm{ml}$ screw-cap flasks containing $50 \mathrm{ml}$ modified mineral media (lacking ammonium phosphate, no new amino acids and enzymes will be synthesized) supplemented with $5 \mathrm{~g} \mathrm{~L}^{-1}$ glucose, $20 \mathrm{~g} \mathrm{~L}^{-1}$ xylose, and $50 \mu \mathrm{l}$ chloramphenicol (inhibiting protein synthesis). Resting cell cultures were maintained at $30{ }^{\circ} \mathrm{C}$ and $100 \mathrm{rpm}$ shaking for $48 \mathrm{~h}$. Samples were taken every $24 \mathrm{~h}$ for analysis of cell mass and the concentration of sugars and fermentation products [13].

\section{Analyses}

Cell mass was estimated by measuring the optical density at $550 \mathrm{~nm}\left(1.0 \mathrm{ml}\right.$ cells of $1.0 \mathrm{OD}_{550 \mathrm{~nm}}$ was approximately $0.33 \mathrm{mg}$ dry weight) using a Unico1100 spectrophotometer with a round culture tube $(1 \mathrm{~cm}$ diameter) as a cuvette [30]. The concentrations of sugars and fermentation products were determined by using high performance liquid chromatography (Waters HPLC) equipped with dual $\lambda$ absorbance and refractive index detectors. Products were separated by using a BioRad HPX $87 \mathrm{H}$ column with $4 \mathrm{mM} \mathrm{H}_{2} \mathrm{SO}_{4}$ as the mobile phase $\left(10 \mu \mathrm{l}\right.$ injection volume, $\left.0.4 \mathrm{ml} / \mathrm{min}, 45^{\circ} \mathrm{C}\right)[25]$.

\section{Results and discussion}

Deletion of the $x y / B$ gene improved the xylose to xylitol conversion ratio

E. coli AI05 (pAI02) was previously engineered for the reduction of xylose to xylitol using the NADH output from glucose catabolism. The fermentation results of AI05 suggested that significant amounts of xylose were metabolized through the pentose phosphate pathway without being reduced to xylitol, representing a significant "substrate loss" [13]. Further analysis showed that the metabolized xylose was at least partially converted into acetate as a by-product $[1,13]$ (Fig. 1c). To prevent xylose loss and minimize acetate by-product accumulation, the $x y l B$ gene encoding for xylulokinase was deleted from AI05, resulting in strain AI09.

Xylose is still expected to be transported into AI09 cells via the XylE transporter, converted to D-xylulose by XylA, but blocked from further metabolism through the pentose phosphate pathway because $x y l B$ deletion blocks Dxylulose to D-xylulose-5 phosphate conversion (Fig. 1c). To evaluate the impact of the $x y l B$ deletion, fermentations were compared using AI05 and AI09 (Fig. 2). The results showed that the $x y l B$ deletion likely prevented some $x y-$ lose loss from metabolism via the pentose phosphate pathway. During the $144 \mathrm{~h}$ fermentation, compared to that of AI05, AI09 produced more xylitol (42.5 vs $34 \mathrm{mM}$ ) and less acetate ( 31 vs $56 \mathrm{mM}$ ), but used an equivalent amount of xylose (60 vs $64 \mathrm{mM}$ ), resulting in an increased xylose to xylitol conversion ratio (1:0.71 vs 1:0.55). Nevertheless, the $x y l B$ deletion resulted in $\mathrm{D}$-xylulose accumulation (data not shown); meaning some of the substrate was lost as an intermediate of the pentose phosphate pathway.

\section{Anaerobic expression of the $s d h C D A B-s u c A B C D$ operon by promoter replacement}

Although the $x y l B$ gene deletion improved the xylose to xylitol conversion ratio, the observed molar yield of xylitol per glucose metabolized $\left(\mathrm{Y}_{\mathrm{RPG}}=3.6\right)$ of AI09 in resting cell fermentation was expected to be similar to the one obtained by the parent AI05 ( $\left.\mathrm{Y}_{\mathrm{RPG}}=3.68\right)$ because a maximal $4 \mathrm{NADH}$ output per glucose catabolized remained the same in both strains. Although this $\mathrm{Y}_{\mathrm{RPG}}$ was comparable to the one reported in literature [1], the majority of the potential reducing power of glucose catabolized remained in the excess acetate due to the fact that the anaerobically growing $E$. coli cells have an incomplete TCA cycle for acetyl-CoA oxidation (partial oxidative and reductive branches). Furthermore, the reductive branch had been blocked by the frdBC deletion in our engineered strain AI05 [13, 29], making the oxidative branch irrelevant. The acetyl-CoA derived from pyruvate oxidation by the anaerobically transcribed pyruvate dehydrogenase complex was unable to be oxidized through TCA cycle, resulting in accumulation of acetate as a by-product. Our hypothesis is that a theoretical $Y_{R P G}$ of 10 could be achieved if all of the reducing power had been extracted from glucose catabolism with the anaerobically active pyruvate dehydrogenase complex and a complete TCA cycle (10 NADH output per glucose catabolized for reduction of 10 xylose to 10 xylitol) (Fig. 1a and c).

Although the enzymatic activity has not been measured, the IcdA (isocitrate dehydrogenase) and AcnAB (isocitrate hydrolyase) should be active (at least in some 

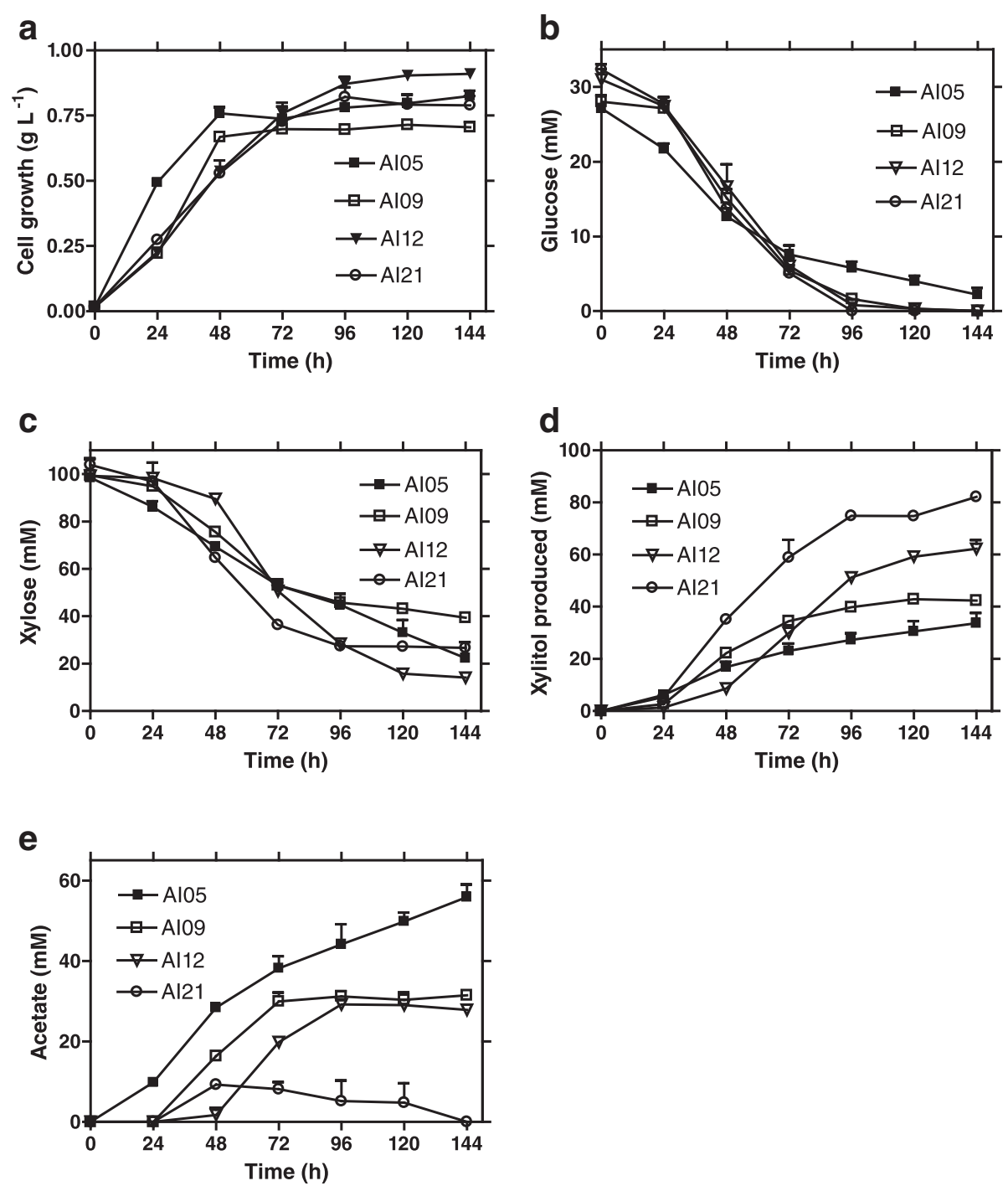

Fig. 2 Xylitol fermentation from glucose $\left(5 \mathrm{~g} \mathrm{~L}^{-1}\right)$ and xylose $\left(15 \mathrm{~g} \mathrm{~L}^{-1}\right)$ mixture. a Cell growth; b Glucose utilization; $\mathbf{c}$ Xylose utilization; d Xylitol production; e Acetate by-product accumulation. Symbols for strain: filled square, Al05; open square, Al09; open triangle, Al12; open cycle, Al21

degree) in our engineered strain because the parent strain can grow anaerobically in glucose minimal medium without supplement of glutamate (data not shown). The incomplete TCA cycle is probably due to the anaerobic repression of the sdhCDAB-sucABCD operon, which encodes for succinate dehydrogenase $(s d h C D A B)$, the $\alpha$-ketoglutarate dehydrogenase complex (sucAB), and succinyl-CoA synthetase (sucCD), three key enzymes needed for a complete TCA cycle [9, 23] (Fig. 1a, broken line). Although there is no guarantee, but very likely, a functional TCA cycle can be established, at least in some degree, by anaerobic expression of sdhCDAB-sucABCD operon. Therefore, a synthetic respiration pathway can be established for reduction of xylose to xylitol, using (theoretic 10) NADH from glucose catabolism via glycolysis, anaerobic expressed pyruvate dehydrogenase and functional TCA cycle.

To enable an anaerobically functional TCA cycle, chromosomal replacement of the native aerobic promoter of the $s d h C D A B-s u c A B C D$ operon with the highly anaerobically functional promoter of the $p f l B$ gene (pflBp6) was performed. In the past, the pflBp6 promoter has been proven quite efficient in the expressing pyruvate dehydrogenase complex (aceEF-lpd, an aerobic operon) under anaerobic conditions $[28,29]$. In addition, an upstream FNR (DNA-binding transcriptional regulator) box and the $p f l B$ ribosomal binding site were included in the promoter replacement for maximal expression of the $s d h C D A B$ sucABCD operon. The resulting strain was designated AI12 (Fnr box-pflBp $p_{(6)}$-sdhCDAB-sucABCD) (Fig. 1b). 
The functionality of the transcriptional fusion of $p f l B \mathrm{p} 6$ and the sdhCDAB-sucABCD operon engineered in E. coli AI12 was initially analyzed by quantitative PCR of the sdhC and sucA transcripts. The results showed that there was a 97, 15, and 10-fold increase in $s d h C$ transcripts in AI12 cells grown on glucose, succinate, and $\alpha$-ketoglutarate, respectively, compared to that of the control. qPCR analysis of the sucA transcripts revealed a similar trend of higher expression in AI12 than that of the control. These results confirmed that the pflBp6 promoter allowed for effective expression of the $s d h C D A B$ suc $A B C D$ operon under oxygen-limiting conditions.

The transcriptional fusion of pflBp6 and $s d h C D A B$ sucABCD was further evaluated by analysis of the activities of $\alpha$-ketoglutarate dehydrogenase and succinate dehydrogenase. The observed succinate dehydrogenase activity of AI12 displayed an 85 and $73 \%$ increase for cells grown in glucose and succinate, respectively, compared to that of the control strain. Similarly, the observed $\alpha$-ketoglutarate dehydrogenase activity displayed a $68 \%$ increase in AI12 over that of the control strain.

\section{Anaerobically functional TCA cycle increased NADH output and xylitol yield per glucose catabolized}

The enhanced enzymatic activities of $\alpha$-ketoglutarate dehydrogenase and succinate dehydrogenase would allow acetyl-CoA oxidation via TCA cycle (Fig. 1a) and resulting in an improved NADH output from glucose catabolism. To evaluate the improvement in the NADH output of the engineered strain, AI12 was compared to its parent strain for cellular concentrations of NADH, NAD, and NADH/NAD ratios by growing cells in sealed screw-cap Erlenmeyer flasks containing $2 \%$ glucose mineral salts medium. Subsequent assays showed a clear increase in the cellular NADH concentration of AI12 (0.0945 $\mathrm{mM} \mathrm{g} \mathrm{DW}^{-1}$ ) compared to that of the parent strain $\left(0.0733 \mathrm{mM} \mathrm{g} \mathrm{DW}^{-1}\right)$. The calculated NADH/ NAD ratios showed that there was about a $45 \%$ increase in reducing power output in AI12 (0.7875) compared to that of the control (0.5414). These results are comparable to NADH/NAD ratios observed in $\operatorname{arcA}$ deletion mutants grown under similar conditions [22]. These results demonstrated that it is possible to increase the potential redox output of the TCA cycle (under anaerobic growth condition) without having to remove the ArcA (transcriptional regulator) and FNR global regulators. One issue still remains from the performed reducing power assays, the loss of reducing power from NADH oxidation by NADH dehydrogenases. However, there is still a clear indication that the anaerobic expression of the sdhCDAB-sucABCD operon increases the reducing power output.

Theoretically, the increased NADH output of glucose catabolism in AI12 would be used to reduce additional xylose to xylitol, resulting in an increase in xylitol yield per glucose catabolized. To test this hypothesis, xylitol fermentations were carried out by the engineered strains carrying plasmid pAI02 using mineral salts medium supplemented with glucose/xylose mixtures $\left(5 \mathrm{~g} \mathrm{~L}^{-1}\right.$ glucose, $15 \mathrm{~g} \mathrm{~L}^{-1}$ xylose) (Fig. 2). During the $144 \mathrm{~h}$ fermentation, strain AI12 used a similar amount of glucose ( 30 vs $28 \mathrm{mM}$ ) (Fig. $2 \mathrm{~b})$, more xylose ( 85 vs $60 \mathrm{mM})$ (Fig. 2c), and produced a significantly higher concentration of xylitol (63 vs $42 \mathrm{mM}$ ) (Fig. 2d) compared to that of the control strain, AI09. Based on these results, the calculated xylitol yield per glucose catabolized in AI12 $\left(\mathrm{Y}_{\mathrm{RPG}}=\right.$ $2.1)$ is significantly higher than that of AI09 $\left(Y_{R P G}=1.5\right)$, which suggests that at least some of the acetyl-CoA was oxidized through TCA cycle, generating extra NADH for xylose reduction. Nevertheless, the xylose to xylitol conversion ratio of AI12 (1:0.74) is similar to the one achieved by AI09 (1:0.72), suggesting that significant amounts of xylose was still lost as D-xylulose.

\section{Deletion of the $x y / A$ gene resulted in a 1:1 xylose to xylitol conversion}

To improve the xylose to xylitol conversion ratio and minimize xylose loss as $\mathrm{D}$-xylulose, the $x y l A$ gene, the first gene in the pentose phosphate pathway for xylose metabolism (Fig. 1c), was deleted from AI12, resulting in strain AI21. This deletion channeled all xylose into xylitol production as confirmed by AI21 fermentations (Fig. 2). Approximately $77 \mathrm{mM}$ xylose was metabolized (Fig. 2c) to produce $\sim 82 \mathrm{mM}$ xylitol (Fig. $2 \mathrm{~d}$ ), suggesting an approximate 1:1 xylose to xylitol conversion in AI21. During this period, $\sim 32 \mathrm{mM}$ glucose was used as a source of reducing power. The calculated $\mathrm{Y}_{\mathrm{RPG}}$ of AI21 was 2.56, although the actual $Y_{\text {RPG }}$ would be over 3 if the glucose used for cell growth $\left(0.79 \mathrm{~g} \mathrm{~L}^{-1}\right)$ was considered (Table 2). It is interesting to note that a significantly decreased acetate accumulation by AI21 strain than that of AI12. This might be attributed to the re-use of acetate by conversion to acetyl-CoA (via acetate synthase (acs)) in AI21 (Fig. 2e) when glucose was completely metabolized after $96 \mathrm{~h}$ fermentation (Fig. 2b). In AI12 fermentation, however, acetate was not re-used because there was some glucose available until $144 \mathrm{~h}$, resulting in accumulation of acetate.

The $Y_{\text {RPG }}$ of 2.56 achieved by AI21 was greater than that of other parent strains, illustrating that greater reducing power output does increase fermentative production of a reduced product. Though this $\mathrm{Y}_{\mathrm{RPG}}$ value is approximately one-third of the theoretical potential of our engineered strain, this is the highest reported molar yield of xylitol produced per glucose consumed in batch cultures grown either aerobically or anaerobically $[7,17,24]$. 
Table 2 Summary of E. coli Al05 (pAGI02) and Al21 (pAGI02) fermentations ${ }^{\text {a }}$

\begin{tabular}{|c|c|c|c|c|}
\hline \multirow[t]{2}{*}{ Parameters } & \multicolumn{2}{|l|}{ Al05 } & \multicolumn{2}{|l|}{$\mathrm{Al} 21$} \\
\hline & Batch & $\begin{array}{l}\text { Resting } \\
\text { cell }\end{array}$ & Batch & $\begin{array}{l}\text { Resting } \\
\text { cell }\end{array}$ \\
\hline Growth $\left(\mathrm{g} \mathrm{L}^{-1}\right)$ & $0.825 \pm 0.02$ & 0 & $0.79 \pm 0.024$ & 0 \\
\hline Glucose used (mM) & $24 \pm 0.89$ & $7.6 \pm 0.05$ & $32 \pm 0.33$ & $7.5 \pm 0.63$ \\
\hline Xylose used (mM) & $75 \pm 6.63$ & $39 \pm 0.2$ & $77 \pm 0.11$ & $47 \pm 0.28$ \\
\hline Xylitol produced (mM) & $34 \pm 3.63$ & $28 \pm 0.68$ & $82 \pm 0.85$ & $45 \pm 0.35$ \\
\hline $\begin{array}{l}\text { Acetate produced } \\
(\mathrm{mM})\end{array}$ & $56 \pm 3.04$ & $18 \pm 1.43$ & 0 & $1 \pm 0.63$ \\
\hline$Y_{R P G}{ }^{b}$ & 1.86 & 3.68 & 3.09 & 6.0 \\
\hline $\begin{array}{l}\text { Xylitol produced/ } \\
\text { xylose used }\end{array}$ & 0.45 & 0.72 & 1.06 & 0.96 \\
\hline Carbon recovery (\%) ${ }^{c}$ & 72 & 81 & 77 & 81 \\
\hline
\end{tabular}

a The data refers to that obtained at the end of fermentation ( $48 \mathrm{~h}$ for resting cell; $144 \mathrm{~h}$ for batch). A $0.5 \%$ glucose and $1.5 \%$ xylose sugar mixture was used for batch fermentation; while a $0.5 \%$ glucose and $2 \%$ xylose sugar mixture was used for resting cell fermentation

${ }^{b}$ The $Y_{R P G}$ was calculated from the total xylitol produced $(\mathrm{mM})$ divided by the total glucose used $(\mathrm{mM})$. For batch fermentation, the glucose used for cell growth was deducted from the total glucose consumed, yielding a $Y_{R P G}$ of 1.86 and 3.09 for Al05 and Al21, respectively

' The carbon recovery was calculated based on two assumptions: 1) the amount of $\mathrm{CO}_{2}$ produced $(\mathrm{mM})$ equals the amount of acetate produced $(\mathrm{mM})$; 2) the carbon weight accounts for $50 \%$ of the cell mass

\section{Resting cell fermentation}

To evaluate the maximal NADH output potential of glucose catabolism by the engineered strain AI21, resting cell fermentations were performed using an equivalent cell density of $\mathrm{OD}_{550} 2.0\left(0.67 \mathrm{~g} \mathrm{~L}^{-1}\right.$ cell mass $)$ in a screw-cap flask filled completely with modified mineral salts medium containing a glucose $\left(5 \mathrm{~g} \mathrm{~L}^{-1}\right)$ and xylose (20 $\mathrm{g} \mathrm{L}^{-1}$ ) mixture, and chloramphenicol. This culture environment allowed cells to be metabolically active with the already available enzymes, but incapable of growth due to the lack of a nitrogen source and inhibition from chloramphenicol (no new enzyme synthesized). During resting cell fermentation, the observed $\mathrm{Y}_{\mathrm{RPG}}$ values exceeded those of batch fermentations (Table 2). AI21 achieved an $\mathrm{Y}_{\mathrm{RPG}}$ of 6 , which is over $60 \%$ higher than that achieved by the parent strain AI05 ( $\mathrm{Y}_{\mathrm{RPG}}$ of 3.68). In addition, there was no loss of xylose to by-products such as xylulose or acetate, confirming the 1:1 xylose to xylitol conversion. Furthermore, the apparent $Y_{\text {RPG }}$ of 6 achieved by AI21 is significantly greater than the maximum previously reported by Cirino et al. ( $\mathrm{Y}_{\mathrm{RPG}} 4.7$ ) (2006).

It is worthy to note that when cell growth is restricted, the theoretical maximum value of $\mathrm{Y}_{\mathrm{RPG}}$ is 10 , correlating with the maximum yield of $10 \mathrm{NADH}$ from the complete oxidation of a molecule of glucose (Fig. 1c). Our most efficient strain, AI21, achieved $60 \%$ of the theoretical maximum $\mathrm{Y}_{\mathrm{RPG}}$. Since there was little acetate production $(\sim 1 \mathrm{mM})$ during resting cell fermentation, acetate accumulation was not attributed to the "missing NADH" per glucose catabolized (10 NADH equivalent potentially). Two possible outcomes of the "missing NADH" would be: 1) the oxidation of NADH through the electron transport system, although this pathway shouldn't be active under anaerobic conditions; 2) the conversion of NADH to NADPH by the transhydrogenase or NADH kinase, although NADPH was reported to be the preferred reducing power used by the aldose reductase of C. boidinii (xylI) [14].

\section{Conclusion}

The E. coli strain AI05 (pAI02) previously engineered for reduction of xylose to xylitol (via synthetic respiration) using the reducing power output from anaerobic glucose catabolism, was further improved by: 1) deleting the $x y l A B$ operon to block xylose loss through the pentose phosphate pathway, achieving a $100 \%$ reduction of xylose to xylitol; 2) anaerobic expressing of the $s d h C D A B$-sucABCD operon to allow acetyl-CoA oxidation via TCA cycle, generating a theoretical $10 \mathrm{NADH}$ output from the catabolism of one glucose for the reduction of 10 xylose to 10 xylitol. The resulting E. coli strain AI21 (pAI02) achieved an actual $100 \%$ reduction of xylose to xylitol, and $60 \%$ of the theoretical maximum xylitol yield per glucose catabolized $\left(\mathrm{Y}_{\mathrm{RPG}}=6\right)$. Nevertheless, an $\mathrm{Y}_{\mathrm{RPG}}$ of 6 is the highest known value reported in literature. Further improvements in the xylitol yield could be achieved by enhancing the conversion of $\mathrm{NADH}$ to NADPH, the preferred reducing power of the aldose reductase of $C$. boidinii ( $x y l I)$ [14]. In addition, this strategy can be used to engineer microbial strains for the homofermentative production of other reduced products from pentose sugars using glucose as a source of reducing power.

\section{Ethics}

Not applicable.

\section{Consent to publish}

Not applicable.

\section{Abbreviations}

aceEF-Ipd: pyruvate dehydrogenase operon; ackA: acetate kinase; $A c n A B$ : isocitrate hydrolyase; adhE: alcohol dehydrogenase; ArcA: transcriptional dual regulator; DCW: dry cell weight; FLP: flipase; FNR: DNA binding transcriptional dual regulator; frd: fumarate reductase; FRT: flipase recognition target; HPLC: high pressure liquid chromatography; IcdA: isocitrate dehydrogenase; LB: Luria Bertani Broth; IdhA: D-lactate dehydrogenase; NAD: nicotinamide adenine dinucleotide; $N A D H$ : reduced form of nicotinamide adenine dinucleotide; $\mathrm{OD}_{550}$ : optical density at $550 \mathrm{~nm}$; PCR: polymerase chain reaction; $\mathrm{PDH}$ : pyruvate dehydrogenase complex; $p d h R$ : repressor of pyruvate dehydrogenase operon; $p f \mid B$ : pyruvate formate lyase; pflBp6: promoter 6 of pyruvate formate lyase; PFT-A: plasmid containing the flipase gene; pKD46: plasmid containing the red recombinase system; PTS: phosphoenolpyruvate phosphotransferase system for sugar transport; ptsG: subunit of glucose PTS permease; sdhCDAB-suCABCD operon: encoding for succinate dehydrogenase, a-ketoglutarate 
dehydrogenase and succinyl-CoA synthetase; TCA: tricarboxylic acid; xy|A: xylose isomerase; $x y \mid B$ : xylulokinase; xylE: xylose/proton symporter; xyll: aldose reductase; $Y_{\text {RPG: }}$ molar yield of xylitol per glucose consumed.

\section{Competing interests}

The authors declare that they have no competing interests.

\section{Authors' contributions}

$\mathrm{Al}$ and SZ designed the study. Al carried out the molecular genetics and fermentation studies. YG participated in fermentation study. SG carried out the quantitative real time PCR analysis. Al, EG, JW, RW and SZ contributed in experiment design, analysis and interpretation of the data, and manuscript writing. All authors have read and approved the final version of the manuscript.

\section{Acknowledgements}

Authors acknowledge the support of the lowa Energy Center (through lowa State University, G5A64055), the University Library Open Access Publishing Fund of Northern Illinois University, IL, USA, and Hubei University of Technology, P. R. China.

\section{Funding}

This research was supported by lowa Energy Center (G5A64055), the University Library Open Access Publishing Fund, Northern Illinois University, IL, USA, and Hubei University of Technology, P. R. China.

\section{Author details}

${ }^{1}$ Hubei Provincial Cooperative Innovation Center of Industrial Fermentation, Key Laboratory of Fermentation Engineering (Ministry of Education), College of Bioengineering, Hubei University of Technology, Wuhan 430068, PR China. ${ }^{2}$ Department of Biological Sciences, Northern Illinois University, DeKalb, IL 60115, USA. ${ }^{3}$ Current address: William Rainey Harper College, Palatine, IL 60142, USA. ${ }^{4}$ School of Life Science, Fujian Normal University, Fuzhou, Fujian 350002, PR China.

Received: 16 January 2016 Accepted: 8 April 2016 Published online: 16 April 2016

\section{References}

1. Akinterinwa O, Cirino PC. Anaerobic obligatory xylitol production in Escherichia coli strains devoid of native fermentation pathways. Appl Environ Microbiol. 2011;77:706-9.

2. Alam KY, Clark DP. Anaerobic fermentation balance of Escherichia coli as observed by in vivo nuclear magnetic resonance spectroscopy. J Bacteriol. 1989;171:6213-7.

3. Amarasingham CR, Davis BD. Regulation of a-ketoglutarate dehydrogenase formation in Escherichia coli. J Biol Chem. 1965;240:3664-8.

4. Aristidou A, Penttila M. Metabolic engineering applications to renewable resource utilization. Curr Opin Biotech. 2000;11:187-98.

5. Berríos-Rivera S. Metabolic engineering of Escherichia coli: increase of NADH availability by overexpressing an NAD + -dependent formate dehydrogenase. Metab Eng. 2002;4:217-29.

6. Berríos-Rivera S, Bennett GN, San K. The effect of increasing NADH availability on the redistribution of metabolic fluxes in Escherichia coli chemostat cultures. Metab Eng. 2002;4:230-7.

7. Cirino PC, Chin JW, Ingram LO. Engineering Escherichia coli for xylitol production from glucose-xylose mixtures. Biotechnol Bioeng. 2006;95:1167-76.

8. Clark DP. The fermentation pathways of Escherichia coli. FEMS Microbiol Rev. 1989;63:223-34.

9. Cunningham L, Guest JR. Transcription and transcript processing in the sdhCDAB-suCABCD operon of Escherichia coli. Microbiology. 1998;144:2113-23.

10. Datsenko KA, Wanner BL. One-step inactivation of chromosomal genes in Escherichia coli K12 using PCR products. Proc Natl Acad Sci U S A. 2000;97: 6640-5.

11. DeGraef MRD, Alexeeva S, Snoep JL, Mattos MJTD. The steady-state internal redox state (NADH/NAD) reflects the external redox state and is correlated with catabolic adaptation in Escherichia coli. J Bacteriol. 1999;181:2351-7.

12. Hederstedt $L$, Rutberg L. Succinate dehydrogenase-A comparative review. Microbiol Rev. 1981;45:542-55.

13. Iverson A, Garza E, Zhao J, Wang Y, Zhao X, Wang J, Manow R, Zhou S. Increasing reducing power output (NADH) of glucose catabolism for reduction of xylose to xylitol by genetically engineered Escherichia coli Al05. World J Microbiol Biotechnol. 2013;29:1225-32.

14. Lee WH, Kim JW, Park EH, Han NS, Kim MD, Seo JH. Effects of NADH kinase on NADPH-dependent biotransformation processes in Escherichia coli. Appl Microbiol Biotechnol. 2013;97:1561-9.

15. Leonardo MR, Dailly Y, Clark DP. Role of NAD regulating the adhE gene of Escherichia coli. J Bacteriol. 1996;178:6013-8.

16. Miller JH. A short course in bacterial genetics: a laboratory manual and handbook for Escherichia coli and related bacteria. Cold Spring Harbor: Cold Spring Harbor Press; 1992.

17. Nair NU, Zhao $\mathrm{H}$. Selective reduction of xylose to xylitol from a mixture of hemicellulosic sugars. Metab Eng. 2010;12:462-8.

18. Nishino K, Inazumi Y, Yamaguchi A. Global analysis of genes regulated by EvgA of the two-component regulatory system in Escherichia coli. J Bacteriol. 2003:185:2667-72.

19. Posfai G, Koob MD, Kirkpatrick HA, Blattner FC. Versatile insertation plasmids for targeted genome manipulations in bacteria: isolation, deletion, and rescue of the pathogenicity island LEE of the Escherichia coli 0157:H7 genome. J Bacteriol. 1997;179:4426-8.

20. Sambrook J, Russell DW. Molecular cloning: a laboratory manual. 3rd ed. Cold Spring Harbor: Cold Spring Harbor Press; 2001.

21. Sandford K, Chotani G, Dodge T, Hsu A, Kumar M, LaDuca R, Trimbur D, Weyler W. The commercial production of chemicals using pathway engineering. Biochem Biophys Acta. 2000;1543:434-55.

22. Shalel-Levanon S, San K, Bennett GN. Effect of oxygen, and ArcA and FNR regulators on the expression of genes related to the electron transfer chain and the TCA cycle in Escherichia coli. Metabol Engineer. 2005;7:364-74.

23. Shen J, Gunsalus RP. Regulation of succinate dehydrogenase (sdhCDAB) operon expression in Escherichia coli in response to carbon supply and anaerobiosis: role of ArcA and Fnr. Mol Microbiol. 1997;26:223-36.

24. Suzuki T, Yokoyama SI, Kinoshita Y, Yamada H, Hatsu M, Takamizawa K, Kawai K. Expression of xyrA gene encoding for $d$-xylose reductase of Candida tropicalis and production of xylitol in Escherichia coli. J Biosci Bioengineer. 1999;87:280-4.

25. Wang Y, Li K, Huang F, Wang J, Zhao J, Zhao X, Garza E, Manow R, Grayburn WS, Zhou S. Engineering and adaptive evolution of Escherichia coli W for Llactic acid fermentation from molasses and corn steep liquor without additional nutrients. Bioresource Technol. 2013;148:394-400.

26. Wimpenny JWT, Firth A. Levels of nicotinamide adenine dinucleotide and reduced nicotinamide adinine dinucleotide in facultative bacteria and the effect on oxygen. J Bacteriol. 1972;111:24-32.

27. Zhou S, Causey TB, Hasona A, Shanmugam KT, Ingram LO. Production of optically pure D-lactic acid in mineral salts medium by metabolically engineered Escherichia coli W3110. Appl Environ Microbiol. 2003;69:399-407.

28. Zhou S, Iverson AG, Grayburn WS. Engineering a native homoethanol pathway in Escherichia coli B for ethanol production. Biotechnol Lett. 2008; 30:335-42.

29. Zhou S, Iverson AG, Grayburn WS. Doubling the catabolic reducing power (NADH) output of Escherichia coli fermentation for the production of reduced products. Biotechnol Prog. 2010;26:45-51.

30. Zhou S, Yomano LP, Shanmugam KT, Ingram LO. Fermentation of $10 \%$ (w/v) sugar to D-lactate by engineered Escherichia coli B. Biotechnol Lett. 2005:27:1891-6.

\section{Submit your next manuscript to BioMed Central and we will help you at every step:}

- We accept pre-submission inquiries

- Our selector tool helps you to find the most relevant journal

- We provide round the clock customer support

- Convenient online submission

- Thorough peer review

- Inclusion in PubMed and all major indexing services

- Maximum visibility for your research

Submit your manuscript at www.biomedcentral.com/submit
Biomed Central 